\title{
State Capacity, Conflict and Development ${ }^{*}$
}

\author{
Timothy Besley ${ }^{\dagger}$ \\ Torsten Persson \pm \\ London School of Economics IIES, Stockholm University
}

The Suntory Centre

Suntory and Toyota International Centres for Economics and Related Disciplines

London School of Economics and Political Science Houghton Street

London WC2A 2AE

Tel: (020) 79556674

\footnotetext{
* This paper is the basis for Persson's Presidential address to the Econometric Society in 2008. We are grateful to Daron Acemoglu and three referees, as well as various participants in regional meetings for comments. We also thank David Seim and Prakarsh Singh for research assistance and CIFAR, ESRC and the Swedish Research Council for financial support.

$\dagger+$ Email: t.besley@lse.ac.uk.

Web: http://econ.lse.ac.uk/staff/tbesley/index_own.html

$\ddagger$ Email: torsten.persson@iies.su.se

Web: http://www.iies.su.se/ perssont/
} 


\begin{abstract}
We report on an on-going project, which asks a number of questions relevant to the study of state capacity. What are the main economic and political determinants of the state's capacity to raise revenue and support private markets? How do risks of violent conflict affect the incentives to invest in state building? Does it matter whether conflicts are external or internal to the state? When are large states associated with higher income levels and growth rates than small states? What relations should we expect between resource rents, civil wars and economic development? The paper is organized into three main sections: 1 . The origins of state capacity, 2. Sate capacity and the genius of taxation, and 3. State capacity and the strategy of conflict. Each of these begins with a specific motivation. A simple model is formulated to analyze the determinants of state capacity in the first section, and modified to address the new issues that arise in subsequent sections. The theoretical results are summarized in a number of propositions. We discuss the implications of the theory, comment on its relation to existing literature, and briefly mention some empiric applications.
\end{abstract}

JEL Codes: O10; H10; P16

Keywords: state capacity; development 
This series is published by the Economic Organisation and Public Policy Programme (EOPP) located within the Suntory and Toyota International Centres for Economics and Related Disciplines (STICERD) at the London School of Economics and Political Science. This new series is an amalgamation of the Development Economics Discussion Papers and the Political Economy and Public Policy Discussion Papers. The programme was established in October 1998 as a successor to the Development Economics Research Programme. The work of the programme is mainly in the fields of development economics, public economics and political economy. It is directed by Maitreesh Ghatak. Oriana Bandiera, Robin Burgess, and Andrea Prat serve as codirectors, and associated faculty consist of Timothy Besley, Jean-Paul Faguet, Henrik Kleven, Valentino Larcinese, Gerard Padro i Miquel, Torsten Persson, Nicholas Stern, and Daniel M. Sturm. Further details about the programme and its work can be viewed on our web site at http://sticerd.lse.ac.uk/research/eopp.

Our Discussion Paper series is available to download at:

http://sticerd.lse.ac.uk/_new/publications/series.asp?prog=EOPP

For any other information relating to this series please contact Leila Alberici on:

Telephone: UK+20 79556674

Fax: $\quad$ UK+20 $\quad$ : $\quad$ (a556951

Email: $\quad$ l.alberici @lse.ac.uk

(C) The authors. All rights reserved. Short sections of text, not to exceed two paragraphs, may be quoted without explicit permission provided that full credit, including (C) notice, is given to the source. 
Analyses of economic development tend to focus on the expansion of the private (market) economy. But development also entails a significant expansion in the size and competence of the state. Just as private physical and human capital accumulation is a key engine of private sector growth, the buildup of public capital is an engine of state expansion. But a good part of investment in state effectiveness comes from improving the ability of the state to implement a range of policies, something which we will refer to as state capacity. Nowadays, this concept is commonplace in other branches of social science and in the wider development community. Coined by historical sociologists, such as Charles Tilly, state capacity originally referred to the power of the state to raise revenue. However, here we broaden it to capture the wider range of competencies that the state acquires in the development process, which includes the power to enforce contracts and to regulate markets.

The paper reports on an on-going project, which asks a number of questions relevant to the study of state capacity. What are the main economic and political determinants of the state's capacity to raise revenue and support markets? How do risks of violent conflict affect the incentives to invest in state building? Does it matter whether conflicts are external or internal to the state? Are large states associated with lower income levels and growth rates than small states? What relations should we expect between resource rents, civil wars and economic development? These questions are now occupying the attention of many scholars who try to understand patterns of development across time and place.

The aim of this paper is to set out a simple unified structure to study these issues. The framework allows us to think clearly about the forces that shape the creation of effective states both in raising revenues and in supporting markets. The paper considers three specific issues: what makes states to invest more in their capacities, what leads them to use market supporting capacity efficiently, and how the possibility of external or internal violence affects these incentives.

The paper has three main sections. The first, on the origins of state capacity, lays out the framework that we adopt and the core modeling choices. The second section, on state capacity and the genius of taxation, explains why building state fiscal capacity can improve other aspects of policy making. The third section, on state capacity and the strategy of conflict, turns to the possibility that the contest for public office is shaped by violent domestic conflict. Using the framework developed in Section 1, we explore the consequences of conflict for investments in state capacity and identify some 
of the channels of influence.

Each of these sections has a similar structure. It begins with a specific motivation. A simple model is formulated to analyze the determinants of state capacity in the first section, and then slightly modified to address the new issues that arise in each subsequent section. The theoretical results in each section are summarized in a few key propositions. We discuss the implications of the theory, comment on its relationship to the existing literature, and mention some empirical work. A short concluding section takes stock of the findings and suggests topics for further research.

\section{The origins of state capacity}

Political and economic historians view the state's capacity to raise revenue as an important phenomenon in itself, a major explanation for military success and, more generally, a key to the successful development of nation states (see e.g., Tilly, 1985, Levi, 1988, or Brewer, 1989). Historically, the tax systems in countries such as the US, the UK, and Sweden, have indeed been reformed and expanded in connection with actual or latent external conflicts. Political scientists such as Migdal (1988) have emphasized that one of the major problems of developing countries is that their states are often too weak and lack the capacity to raise revenue and to govern effectively.

By contrast, economists generally pay little attention to state capacity. Researchers in public finance, political economics, or development rarely assume that a government, which finds a certain tax rate for a certain tax base optimal and incentive-compatible, is constrained by fiscal infrastructure. Similarly, economic theory typically does not assume that the state is constrained by a lack of legal infrastructure, when it comes to enforcing private contracts or, more generally, supporting private markets.

Presupposing sufficient capacities to tax and support markets does not rhyme well with the experience of many states, either in history or in the developing world of today. Moreover, international data suggest that the ability to raise revenue from advanced tax systems is strongly positively related to the ability to support markets, as well as to the level of economic development.

Figure 1 is a good starting point to motivate these thoughts. It illustrates the positive correlations in contemporary data between the share of GDP raised by an income tax (vertical axis), the ratio of private credit to GDP 
(horizontal axis), and income (blue dots above, and red dots below, median income). There is no good reason to believe that these correlations can be interpreted causally. Indeed, our core model's explanation of them will emphasize their joint determination with institutions, historical shocks and initial conditions being common omitted factors that drive all three of these variables.

The approach that we take follows Besley and Persson (2008a). ${ }^{1}$ A key feature of the theoretical approach that follows is to separate government decisions about resources to enhance the feasible set of policies, and decisions about the policies themselves. Thus, taxes and market-supporting policies are constrained by the state's fiscal and legal capacity. We model the expansion of these capacities as forward-looking investments under uncertainty. A central result that emerges from the framework, under specific assumptions, is an important complementarity between fiscal and legal capacity. This implies that the two forms of state capacity are likely to be positively correlated with each other and with income, as we find in Figure 1.

\subsection{Basic model setup}

There are two groups. Each comprises half the population in every period and total population size is normalized to one. For the purposes of this paper, two alternative timing structures give essentially the same results. In one, time is infinite and one generation is alive in each period, making investment decisions based on a warm-glow bequest motive. In the other, which we will adhere to here, there are just two time periods, $s=1,2$, and the world ends after period 2. Although artificial, this two-period approach allows us to make the main points of economic interest.

At the beginning of period 2, the group that held power at the end of period 1 is the incumbent government, denoted by $I_{1}$. The other group is the opposition denoted by $O_{1}$. Power can be peacefully transferred to the opposition, which happens with exogenous probability given by parameter $\gamma$. As a result, whoever wins becomes the new incumbent, $I_{2}$, and whoever loses becomes the new opposition, $\mathrm{O}_{2}$. At the end of period $s$, the current incumbent, $I_{s}$, sets a tax on the income of each group member denoted by

\footnotetext{
${ }^{1}$ Related papers include Acemoglu (2005), where governments can increase their future tax revenues by spending on public goods, and Acemoglu, Ticchi and Vindigni (2007) who study the build up of government bureaucracies. Fiscal capacity has been studied by Cukierman et al (1992) and legal capacity investment by Svensson (1998).
} 
$t^{J_{s}}$, where $J_{s} \in\left\{I_{s}, O_{s}\right\}$. It also chooses a level of legal support for each group $p^{J_{s}}$, and spends on general public goods $G_{s}$. At the end of period 1, incumbent $I_{1}$ also makes investments in next period's state capacity (see below). In addition to tax income, the government(s) earns natural resource rents $R_{s}$. These are stochastic and drawn from a two-point distribution $\left\{R_{L}, R_{H}\right\}$ where $R_{s}=R_{H}$ with probability $\rho$ in each period. None of the resource rents accrue directly to the private sector. ${ }^{2}$ Natural resource rents will play their most important role in Section 3.

The precise timing of these different events are spelled out below.

Individual incomes and utility In period $s$, individuals consume and produce, with members of group $J_{s}$ earning a market income:

$$
w^{J_{s}}=w\left(p^{J_{s}}\right)
$$

where $w(\cdot)$ is an increasing concave function. The policy variable $p^{J_{s}}$ can be interpreted in a number of ways. In a broad sense, we view it as a reduced form for market supporting policies that raise private incomes. This might include the provision of various forms of physical infrastructures The distinctive feature of policy is that the way capacity is deployed, reflected by $p^{J_{s}}$, is distinct from the capacity to use the policy, a feature that we introduce below. Following Besley and Persson (2008a) we will refer throughout to $p^{J_{s}}$ as if they are policies that affect legal enforcement and raise incomes by facilitating gains from trade in capital markets. ${ }^{3}$

Individual utility in period $s$ is linear and described by:

$$
\alpha_{s} G_{s}+c^{J_{s}}=\alpha_{s} G_{s}+\left(1-t^{J_{s}}\right) w\left(p^{J_{s}}\right)
$$

where $c^{J_{s}}$ is private consumption, and $G_{s}$ is the level of public goods with parameter $\alpha_{s}$ reflecting the value of public goods. A specific interpretation is that $G_{s}$ denotes spending on external defense and $\alpha_{s}$ the risk of external conflict. We assume that $\alpha_{s}$ has a two point distribution $\left\{\alpha_{L}, \alpha_{H}\right\}$, with

\footnotetext{
${ }^{2}$ We could add private natural resources as accruing additively to private incomes without any affect on the incentives that we model in this paper. In this case, $R_{s}$ can be thought of as the share of rents that accrue to the public sector.

${ }^{3}$ Besley and Persson (2008a) develop a microfounded model with less than perfect enforcement (by the state) of collateral in (private) credit-market contracts. The policy $p^{J_{s}}$ in this context is interpreted as policies that allow greater use of collateral to support trade in credit markets.
} 
$\alpha_{H}>2$ and $\alpha_{L}<1$, and we use $\phi$ to denote the probability that $\alpha_{s}=$ $\alpha_{H}$. The equality in (1) arises since we assume that individuals do not save between periods 1 and 2 .

Constraints on government Policies are constrained by state capacity. The levels of fiscal capacity $\tau_{s}$, and legal capacity $\pi_{s}$ are inherited from the previous period. The incumbent group in period 1 chooses these levels for period 2 subject to the political institutions in place (see below).

In concrete terms, $\tau$ represents fiscal infrastructure such as a set of competent tax auditors, or the institutions necessary to tax income at source or to impose a value-added tax - we can think about $\tau$ as decreasing the share of her market income $(1-\tau)$ an individual can earn in the informal sector. Fiscal capacity does not depreciate, but can be augmented by $I_{1}$ through non-negative investments which $\operatorname{cost} F\left(\tau_{2}-\tau_{1}\right)$, where $F(\cdot)$ is an increasing convex function with $F(0)=F_{\tau}(0)=0$. A higher $\tau_{s}$ allows the incumbent $I_{s}$ to charge higher tax rates, such that $t^{J_{s}} \leq \tau_{s}$. To allow for redistribution in a simple way, we allow negative tax rates.

In concrete terms, $\pi$ represents legal infrastructure investments such as building court systems, educating and employing judges and registering property or credit. Like fiscal capacity, legal capacity does not depreciate, but can be augmented with non-negative investments at cost $L\left(\pi_{2}-\pi_{1}\right)$, where $L(\cdot)$ is an increasing convex function with $L(0)=L_{\pi}(0)=0$. A higher $\pi_{s}$ allows government $I_{s}$ to better support private markets with $0 \leq p^{J_{s}} \leq \pi_{s}$.

The government budget constraint in period $s$ can be written

$$
0 \leq \sum_{J_{s} \in\left\{I_{s}, O_{s}\right\}} \frac{t^{J_{s}} w^{J_{s}}}{2}-G_{s}+R_{s}- \begin{cases}L\left(\pi_{2}-\pi_{1}\right)-F\left(\tau_{2}-\tau_{1}\right) & \text { if } s=1 \\ 0 & \text { if } s=2\end{cases}
$$

Political institutions As mentioned above, power can shift exogenously between the groups. Because the opposition takes over with probability $\gamma$, this parameter becomes a crude measure of political instability.

We assume political institutions make incumbent governments internalize the preferences of the opposition, to some degree. Specifically, an incumbent attaches weights $\theta$ to the opposition group and $(1-\theta)$ to its own group, where $\theta \in\left[0, \frac{1}{2}\right]$. This parameterization captures, albeit in a simple and reducedform way, the representativeness of political institutions through checks and balances or electoral systems. When checks and balances are very strong, the 
incumbent behaves like a Utilitarian planner - treating both groups equally - in which case $\theta=\frac{1}{2}$. At the other extreme, an omnipotent autocrat faces no executive constraints and behaves as if $\theta=0$.

Timing Each period has the following timing:

1. The initial conditions are $\left\{\tau_{s}, \pi_{s}\right\}$ and the identity of last period's incumbent $I_{s-1}$.

2. The value of public goods $\alpha_{s}$ and natural resource rents $R_{s}$ are realized.

3. Group $I_{s-1}$ remains in office with probability $1-\gamma$.

4. The new incumbent $I_{s}$ determines a vector of tax rates, legal support, and spending on public goods: $\left\{\left\{t^{J_{s}}, p^{J_{s}},\right\}_{J_{s} \in\left\{I_{s}, O_{s}\right\}}, G_{s}\right\}$. The period-1 incumbent also chooses state capacities for the next period $\tau_{2}, \pi_{2}$.

5. Payoffs for period $s$ are realized and consumption takes place.

\subsection{Equilibrium policy}

We begin with the policy choices at stage 4 of period $s$. Linearity allows us to study these separately from the choices of state capacity for period 2 . With the assumed policy weights, we can write the objective of incumbent $I_{s}$ as:

$$
\begin{aligned}
V^{I_{s}}= & (1-\theta) w\left(p^{I_{s}}\right)\left(1-t^{I_{s}}\right)+\theta w\left(p^{O_{s}}\right)\left(1-t^{O_{s}}\right)+ \\
& \alpha_{s}\left[\frac{t^{I_{s}} w\left(p^{I_{s}}\right)+t^{O_{s}} w\left(p^{O_{s}}\right)}{2}+z_{s}\right],
\end{aligned}
$$

where we have replaced $G_{s}$ via the government budget constraint (2), and where residual revenue $z_{s}$ is defined by

$$
z_{s}=R_{s}- \begin{cases}L\left(\pi_{2}-\pi_{1}\right)-F\left(\tau_{2}-\tau_{1}\right) & \text { if } s=1 \\ 0 & \text { if } s=2 .\end{cases}
$$

This objective is maximized subject to $G_{s} \geq 0, t^{J_{s}} \leq \tau_{s}$ and $p^{J_{s}} \leq \pi_{s}$. 
Taxation and spending on public goods The simple form of (3) makes it easy to derive equilibrium fiscal policy. Whenever $\alpha_{s}=\alpha_{H}>2(1-\theta)$, it is optimal for $I_{s}$ to tax its own group maximally, $t^{I_{s}}=\tau_{s}$, and use the revenue to expand $G_{s}$. Because $I_{s}$ puts weight $\theta \leq 1-\theta$ on the opposition group, it also sets $t^{O_{s}}=\tau_{s}$. If $\alpha_{s}=\alpha_{L}<2(1-\theta)$, it becomes optimal to switch to a redistributive policy, where the opposition is still taxed fully, $t^{O_{s}}=\tau_{s}$, but no public goods are provided and

$$
-t^{I_{s}} w\left(p^{I_{s}}\right)=\tau_{s} w\left(p^{O_{s}}\right)+2 z_{s} .
$$

Thus, whether we have high or low demand for common-interest public goods is crucial. For high $\alpha$, the incumbent taxes both groups at fiscal capacity and spends all available revenue (less investment costs if $s=1$ ) on public goods. When public goods are not very valuable, no public goods are provided and all available revenue is transferred to the incumbent group (through a negative tax rate). We refer to $\alpha_{s}=\alpha_{H}$ is the common-interest state, and to $\alpha_{s}=\alpha_{L}$ as the redistributive state.

The realized value of government funds in period $s$, which is obtained by differentiating $V^{I_{s}}$ with regard to $z_{s}$ in the two cases, is therefore given by

$$
\lambda_{s}=\operatorname{Max}\left[\alpha_{s}, 2(1-\theta)\right] .
$$

Besley and Persson (2008a) emphasize that unless $\theta=\frac{1}{2}$ the political equilibrium will underprovide public goods relative to a Utilitarian planner. ${ }^{4}$ However, given our assumptions about the two potential values of $\alpha_{s}$, the underprovision effect is absent here.

Legal protection It is easy to see that (3) is increasing in the legal protection of each group. Thus, it becomes optimal to exploit any existing legal capacity fully and set

$$
p^{O_{s}}=p^{I_{s}}=\pi_{s} .
$$

Intuitively, the incumbent group can only gain from improving property rights to both groups, either directly via a higher wage, or indirectly via a higher tax base. Simple as it is, this production efficiency result is in the

\footnotetext{
${ }^{4}$ Our assumptions that $\alpha_{H}>2$ and $\alpha_{L}<1$ ensure that there is always spending on public goods when $\alpha_{s}=\alpha_{H}$ and transfers when $\alpha_{s}=\alpha_{L}$ which coincides with the Utilitarian optimum.
} 
spirit of Diamond and Mirrlees (1971). The result does not mean that property rights are well protected everywhere, however, since this hinges on the chosen value of $\pi_{s}$. Moreover, Section 2 will identify a set of circumstances when production efficiency fails and the incumbent does not fully exploit legal capacity for the opposition group.

Even though the setup is a bit different, the results on policy are similar to those in Besley and Persson (2008a). Collecting all of these results, we have:

Proposition 1 In all states $p^{J_{s}}=\pi_{s}$ for $J_{s} \in\left\{I_{s}, O_{s}\right\}$ and $t^{O_{s}}=\tau_{s}$. In common interest states, $G_{s}=\tau w\left(\pi_{s}\right)+z_{s}$ and $t^{I_{s}}=\tau_{s}$, while in redistributive states, $G_{s}=0$ and $-t^{I_{s}}=\tau_{s}+2 \frac{z_{s}}{w\left(\pi_{s}\right)}$.

\subsection{Equilibrium state capacity}

Preliminaries Using the equilibrium policies in Proposition 1, we can write the expected future payoff to the incumbent at stage 4 of period 1, taking as given the state capacity for period 2. This is given by:

$$
E\left[V^{I_{1}}\left(\pi_{2}, \tau_{2}\right)\right]=w\left(\pi_{2}\right)\left(1-\tau_{2}\right)+E\left(\lambda_{2}\right)\left[\tau_{2} w\left(\pi_{2}\right)+E\left(z_{2}\right)\right] .
$$

where $E\left(\lambda_{2}\right)=\phi \alpha_{H}+(1-\phi) 2[(1-\theta-\gamma(1-2 \theta)]$ is the expected value of government funds in period 2 , as seen from period 1 . As we shall see, $E\left(\lambda_{2}\right)$ is a key magnitude determining investment incentives.

State capacity choices The choice by incumbent group $I_{1}$ of state capacity for period 2 maximizes:

$$
E\left[V^{I_{1}}\left(\pi_{2}, \tau_{2}\right)\right]-\lambda_{1}\left[L\left(\pi_{2}-\pi_{1}\right)+F\left(\tau_{2}-\tau_{1}\right)\right],
$$

subject to $\pi_{2} \geq \pi_{1}$ and $\tau_{2} \geq \tau_{1}$. Thus the choice of $I_{1}$ trades off the period 2 expected benefits against the period 1 costs of investment, given the realized value of public funds. When doing so, it takes into account the uncertainties about the future values of public goods and resource rents, as well as the prospects of government turnover.

Carrying out the maximization and using (4), we can write the first-order (complementary-slackness) conditions as:

$$
w_{p}\left(\pi_{2}\right)\left\{1+\tau_{2}\left[E\left(\lambda_{2}\right)-1\right]\right\} \leq \lambda_{1} L_{\pi}\left(\pi_{2}-\pi_{1}\right)
$$


and

$$
w\left(\pi_{2}\right)\left[E\left(\lambda_{2}\right)-1\right] \leq \lambda_{1} F_{\tau}\left(\tau_{2}-\tau_{1}\right),
$$

where (6) concerns legal capacity and (7) fiscal capacity.

Conditions (6) and (7) reproduce, in somewhat different notation, the gist of the results in Besley and Persson (2008a). Since $L_{\pi}(0)=F_{\tau}(0)=0$, it is easy to see that if $E\left(\lambda_{2}\right)>1$ there is always positive investment in both kinds of state capacity. Moreover, in this case which we will focus on here, fiscal and legal capacity are complements. This case will prevail as long as $\phi$ is large enough, i.e. there is a sufficiently high probability of the common interest state, or $\theta$ is close enough to $1 / 2$ and/or $\gamma<1 / 2$, i.e., there is sufficient political stability.

Determinants of state capacity If $E\left(\lambda_{2}\right)>1$, then the left hand side of (6) is increasing in $\tau_{2}$, while the left hand side of (7) is increasing in $\pi_{2}$. The resulting complementarity is interesting in its own right. However, it also simplifies the analysis since it implies that the payoff function (5) is supermodular. This means that we can use standard results on monotone comparative statics (see, for example, Milgrom and Shannon, 1994). Thus, any factor that increases (decreases) the expected value of government funds $E\left(\lambda_{2}\right)$, for given $\lambda_{1}$, will increase (decrease) investment in both legal and fiscal capacity. The same is true for any factor that weakly decreases (increases) the RHS of the two expressions for given $E\left(\lambda_{2}\right)$.

Using (6) and (7) together with the definition of $E\left(\lambda_{2}\right)$, we establish the following result:

Proposition 2 Investments in both legal and fiscal capacity increase with:

1. wages

2. the share of national income not generated by natural resources

3. the value of public goods

4. the level of political stability and with more inclusive political institutions, as long as political instability is high enough $(\gamma \geq 1 / 2)$

5. a lower cost of investment in either type of investment (for given $\pi$ or $\tau)$

The proof of this and subsequent results is found in the Appendix. 


\subsection{Implications}

The first part of Proposition 2 is consistent with Figure 1, where we saw that taxation and financial development are both positively correlated with income across countries. However, the result also makes clear that causation runs from income to market support and taxation, not the other way around. The result is also consistent with an argument made by Rajan and Zingales (2003) that financial development is positively correlated with openness to international trade (as the latter expands the returns to reallocating capital). It is also consistent with their historical evidence that financial development and openness have co-varied over the last century. We return to the relation between financial development and income (growth) below.

Second, Proposition 2 suggests that investment in state capacity is declining in the share of resource rents in GDP $-R_{s} / Y_{s}=R_{s} /\left(w\left(\pi_{s}\right)+R_{s}\right)$ - for given $Y_{s}$. This is because we have assumed that only produced output is taxed and that legal capacity is only useful for produced output.

The third part of Proposition 2 is in line with Tilly's (1985) claim that war is important for building fiscal capacity, but extends it to legal capacity. While external defense is a natural example, the result applies to any national common-interest program, such as a universal welfare state or health program. If the demand for such public goods or services is expected to be high, any group that is in power has a greater incentive to invest in fiscal capacity to finance future common-interest spending.

Part four of the Proposition holds because the incumbent group faces a smaller risk of the opposition using a larger fiscal capacity to redistribute against the incumbent. The effect of instability is larger, the closer is $\theta$ to zero, i.e. when institutions are less inclusive. Thus, we should not only observe higher political stability to induce more developed economic institutions, but a particularly large effect in countries with less representative political systems. We know of no systematic evidence on such interactions, but a historical case in point is England after the Glorious Revolution. During a parliament dominated by the Whigs for more than 40 years, tax income rose to $20 \%$ of GDP, and institutions for charging excise and indirect taxes were put in place (see e.g., Stasavage, 2007, and O'Brien 2005). In the second half of the 18th century, continued state capacity building by the dominant British elite culminated in the launch of an income tax during the Napoleonic wars, when the British government could raise taxes equal to a remarkable $36 \%$ of GDP (Mathias and O'Brien, 1976). 
The effect of an increase in the representativeness of political institutions is more uncertain. It is relevant only when political stability is low enough as might be the case after a transition to democracy that loosens the grip of one group on power. When stability is low, increasing inclusiveness works since more representative political institutions lowers the expected value of redistribution. As the state becomes more focused on common interests, the value of fiscal capacity goes up and, by complementarity, so does the value of legal capacity. A long tradition in political science, e.g., Lijphart (1999), considers proportional electoral systems more consensual than majoritarian systems, while Persson, Roland and Tabellini (2000) argue that parliamentary democracies are more representative than presidential democracies. By the proposition, legal and fiscal capacity should be especially higher in such democracies.

One interpretation of fifth part of the proposition is a theoretical rationale for legal origins, the subject of many studies following La Porta et al (1998). If some form of legal origin, such as the common-law tradition, makes it cheaper to facilitate private contracting, then we would expect this to promote investments in the legal system. Less trivially, we would also expect the same legal origin to promote investments in the tax system, because of the complementarity of legal and fiscal capacity.

Correlations in international data Besley and Persson (2008a) explore the cross-sectional correlations in international data, motivated by results like Proposition 2, which identifies a number of common determinants of legal and fiscal capacity. ${ }^{5}$ First, they take the historical incidence of war as a proxy for the past demand for common public goods and use data from the Correlates of War data set to measure the share of all years between 1816 or independence, if later - and 1975 that a country was involved in external military conflict. Second, they take the historical incidence of democracy or parliamentary democracy, as proxies for inclusive political institutions, and use data from the Polity IV data set to measure the share of years from 1800 (or independence) to 1975 that a country had these institutions. Third, they consider indicators of legal origin from La Porta et al (1998) as proxies for the cost of legal infrastructure. To gauge current legal and fiscal capacity, they consider four different indicators of each form of state capacity, including

\footnotetext{
${ }^{5}$ To facilitate interpretation, all the variables are scaled to lie between 0 and 1 . For more on the data, see Besley and Persson (2008a)
} 
measures of contract enforcement, protection of property rights, and various aspects of tax structure.

Besley and Persson (2008a) show that a higher share of external conflict years in the past is always associated with higher measures of legal capacity as well as fiscal capacity in the present. Past incidence of democracy or parliamentary democracy (the two variables are closely related) correlate positively with both types of state capacity. While English legal origin is uncorrelated with legal capacity (except when it comes to contract enforcement), German and Scandinavian legal origins do display a robust positive correlation, not only with legal capacity but also with fiscal capacity. Several determinants identified by our theory appear to have stable correlations with the state's capacity to support markets as well as to raise revenue.

Growth Beyond these direct implications, the model makes a prediction about economic growth between periods 1 and 2. Using Proposition 1, this is given by:

$$
\frac{Y_{2}-Y_{1}}{Y_{1}}=\frac{w\left(\pi_{2}\right)-w\left(\pi_{1}\right)+R_{2}-R_{1}}{w\left(\pi_{1}\right)+R_{1}} .
$$

If we ignore the exogenous resource rents, higher growth is generated solely by having higher legal capacity and hence better support for private markets. This would show up in the data as higher TFP.

Legal capacity may be closely related to financial development (in the microfounded model of Besley and Persson, (2008a), e.g., private credit to GDP is proportional to $\pi$ ). Financial development due to better institutions can thus cause growth. But the relationship can easily go the other way: according to the second part of Proposition 2, higher income generally raises incentives to invest in legal capacity leading to financial development.

The complementarity between fiscal and legal capacity has interesting implications for the relationship between taxation and growth. If greater legal capacity is driven by the determinants suggested by Proposition 2, we would expect it go hand-in-hand with greater fiscal capacity. Variation in these determinants would tend to induce a positive correlation between taxes and growth. Even in the case where $E\left(\lambda_{2}\right)<1$ (when investment in fiscal capacity is zero), legal capacity and national income are still positively correlated even though taxation and growth are uncorrelated. ${ }^{6}$

\footnotetext{
${ }^{6}$ However, Besley and Persson (2008a) show that changes in income distribution drive fiscal and legal capacity in opposite directions, inducing a negative correlation between
} 
These observations relate to recent empirical findings in the macroeconomics of development. Many researchers have found a positive correlation between measures of financial development, or property-rights protection, and economic growth (e.g., King and Levine, 1993, Hall and Jones, 1999 and many subsequent papers), although the first part of Proposition 2 warns us that such correlations may not reflect a causal effect of financial markets, but reverse causation. But many researchers who expected to find a negative relation between taxes and growth have found nothing (see e.g., the overview in Benabou, 1997). Simple though it is, our model suggests a possible reason for these findings.

We have focused our modeling on state capacity and hence ignored the standard engine of growth through private capital accumulation. When one extends the model with private investment, building fiscal capacity does have a more "standard" disincentive effect on growth because higher $\tau_{2}$ raises expected taxes and lowers expected net private returns. However, building legal capacity has an additional positive effect on growth, because it can raise gross returns to investing, which stimulates private accumulation. With complementarity between fiscal and legal capacity, both kinds of state capacity may still expand with overall income.

\section{State capacity and the genius of taxation}

The expansion of government activity and taxation is one of the most striking economic facts observed over the last century. The causes behind large and growing government are the subject of much research in economics and other social sciences, including recent work in political economics. Our approach offers a distinctive perspective on these issues.

Drawing on broader discussions about government intervention, one finds two main opposing perspectives on the growth of government. Some observers adopt a view rooted in benevolent government, seeing growth of government as a manifestation of the government's role in redistribution and correction of market failures, such as the under-supply of public goods. Others take a more malevolent view, arguing that large government reflects abuse of power or rent seeking.

Both stylized views stem from somewhat simplistic views about the motives of governments and the way in which they redistribute resources. The

taxes and growth. 
benevolent government view ignores the reality that some government activities are indeed hard to square with social-welfare maximization and that vested interests play a role in policy formation. The malevolent view tends to place too much emphasis on the use of taxes in redistribution, ignoring the fact that, when a tax system is poorly developed, redistribution may be carried out in much less efficient ways not picked up by conventional measures of government size. This view also fails to recognize that suppressing vested interests may not be politically feasible.

In the data, evidence on the costs of large government is mixed. As mentioned above, it is hard to find evidence in macroeconomic studies of aggregate data that high taxes affects the growth rate. Most microeconomic studies of individual data also tend to find fairly modest behavioral effects of taxes on investment behavior.

The standard view of government's role in enhancing growth developed, for example, by Barro (1990) and Barro and Sala-i-Martin (1992) emphasizes the role that tax-financed public capital accumulation, such as building ports and roads, can play in increasing national income. This is clearly important. We, however, offer a somewhat different focus emphasizing that investments in fiscal capacity can lead to an efficiency-enhancing change in the form of redistribution, diminishing the use of other "regulatory" distortions which make the economy less productive.

In this section, we develop an example where large government - meaning high fiscal capacity - may be beneficial. By eliminating more costly forms of redistribution, large government may yield higher production and national income than small government even if government revenues are used to fund transfers. The key observation is that redistribution using taxation is generally less costly than redistribution through distorting the allocation of market supporting policies. This "genius of taxation" argument is really a positiveeconomics application of Diamond and Mirrlees (1971) results on production efficiency, which we alluded to in Section 1.2. Government without access to sufficient fiscal capacity may choose legal protection in an inefficient way. Most importantly in a dynamic setting, the resulting inefficiency may be an equilibrium outcome when state capacity is chosen endogenously.

In order to make these points, we extend the basic model in Section 1.1 in a modest way by adding an additional factor of production which becomes a source of producer rents. It is these rents that can generate the inefficiency. 


\subsection{A simple two-factor economy}

Suppose now that $w\left(p^{J_{s}}\right)$ is a form of capital, the productivity of which depends on property-rights protection for group $J$ in period $s$. A share of each group, denoted by $\sigma$, are entrepreneurs and have access to a constantreturns Cobb-Douglas technology that combines capital and raw labor, $l$, to produce output. The capital share is denoted by $\eta .{ }^{7}$ The remaining $1-\sigma$ share of the population supplies a single unit of raw labor to an economy-wide labor market. We write the production technology in intensive form as $l^{J_{s}}\left(k^{J_{s}}\right)^{\eta}$, where $k^{J_{s}}$ is the capital-to-labor ratio $w\left(p^{J_{s}}\right) / l^{J_{s}}$. Because aggregate labor supply is $l=(1-\sigma)$, we can write the aggregate capital-labor ratio

$$
k\left(p^{I_{s}}, p^{O_{s}}\right)=\frac{\sigma\left[w\left(p^{I_{s}}\right)+w\left(p^{O_{s}}\right)\right]}{2(1-\sigma)},
$$

as an increasing function of the property-rights protection of each group. For an individual capital owner in group $J_{s}$, the optimal labor demand satisfies the first-order condition $(1-\eta)\left(k^{J_{s}}\right)^{\eta}=\omega$, where $\omega$ is the economy-wide wage. As the technology is common across groups, the equilibrium wage is given by the same condition, evaluated at the aggregate capital-labor ratio:

$$
(1-\eta)\left(k\left(p^{I_{s}}, p^{O_{s}}\right)\right)^{\eta}=\omega\left(p^{I_{s}}, p^{O_{s}}\right) .
$$

Thus, the wage depends on property-rights protection for the two groups. Moreover, it is increasing in both of these policy variables, because

$$
\frac{\partial \omega}{\partial p^{J_{s}}}=(1-\eta) \eta\left(k\left(p^{I_{s}}, p^{O_{s}}\right)\right)^{\eta-1} \frac{\sigma w_{p}\left(p^{J_{s}}\right)}{2(1-\sigma)}>0 .
$$

Intuitively, more productive capital in any sector drives up the demand for labor which raises the equilibrium wage.

Finally, we can define the income of a representative member of group $J_{s}$ as

$$
y^{J_{s}}\left(p^{I_{s}}, p^{O_{s}}\right)=(1-\sigma) \omega\left(p^{I_{s}}, p^{O_{s}}\right)+\sigma l^{J_{s}}\left[\left(k^{J_{s}}\right)^{\eta}-\omega\left(p^{I_{s}}, p^{O_{s}}\right)\right] .
$$

This is the sum of labor income and rental income from owning capital. Compared to the basic model, income of group $J_{s}$ now depends on the legal

\footnotetext{
${ }^{7}$ Assuming a common share $\sigma$ across groups simplifies the algebra. Relaxing this assumption makes it easier to prove the possibility of inefficient outcomes (see Propositions 3 and 4). An incumbent group, $I$, with a large share $\sigma^{I}$ of capital owners is more willing to select inefficient policies to boost the group's rents than is a group with a small share.
} 
protection of the other group as well, through the endogenous equilibrium wage. The latter has a positive effect on group members with raw labor (the first term on the right hand side of (9)), but a negative effect on those earning quasi-rents on their capital (the second term on the right hand side).

\subsection{Policy and state capacity}

For the rest, the model works exactly as in Section 1. To analyze optimal policy, we replace $w\left(p^{J_{s}}\right)$ in (3) by the new income function $y^{J_{s}}\left(p^{I_{s}}, p^{O_{s}}\right)$ in (9). The main consequence is that, if $\sigma$ is high enough, then an incumbent group $I_{s}$ may prefer to keep wages low. Moreover, the ruling group can engineer a lower wage by blocking the opposition group's access to legal capacity and hence driving down the demand for labor.

Going through similar steps to those in Section 1.2, we can show:

Proposition 3 If $\theta=\frac{1}{2}$ or $\tau_{s}=1$, then legal capacity is always fully utilized for both groups. There exists a threshold $\widehat{\tau}(\theta, \alpha)$, such that the legal protection of the opposition group is minimal: $p^{O_{s}}=0$ for all $\tau_{s}<\widehat{\tau}(\theta, \alpha)$, and where $\widehat{\tau}_{\theta}(\theta, \alpha)<0$, and $\widehat{\tau}_{\alpha}(\theta, \alpha)<0$ if $\alpha=\alpha_{H}$.

This result says that there is always production efficiency in the Utilitarian case, or when fiscal capacity is high enough. However, when fiscal capacity is below a critical threshold, a politically motivated incumbent may prefer an inefficient policy which lowers the level of national income. In this specific example, maximizing (gross) income and using the tax system for redistribution may be less useful to the incumbent than distorting production and raising quasi-rents by maintaining a supply of low-wage labor. ${ }^{8}$

Proposition 3 shows that the critical threshold for fiscal capacity depends on institutions and circumstances. When political institutions are more inclusive, as parameterized by a higher $\theta$, existing fiscal capacity must be lower to trigger inefficiently low legal protection for the opposition. Similarly, in a common-interest state, with $\alpha_{s}=\alpha_{H}>2(1-\theta)$, the critical threshold for fiscal capacity is lower than in a redistributive state.

\footnotetext{
${ }^{8}$ There is an analogy here with Diamond and Mirrlees (1971) who argue that production efficiency is desirable if a tax system is sufficiently rich. One of the assumptions required in their framework is that there be $100 \%$ taxation of pure profits. In our model all income is taxed at the same rate and hence $\tau_{s}=1$ is effectively equivalent to full taxation of pure profits (the rents on capital).
} 
The observation that limited powers to use taxation for redistribution can lead to distorted factor markets is not new. In particular, this line of argument is developed by Acemoglu (2006). However, to provide a complete explanation requires some understanding of why the state lacks the power to tax. This can be addressed only if fiscal capacity is endogenous.

The results from the previous section, particularly Proposition 2, give us a stepping stone for the required analysis. We now apply this logic to understand why $\tau$ can remain low (below the threshold required for production efficiency). Our key result is

Proposition 4 Suppose that $\tau_{1}<\hat{\tau}\left(\theta, \alpha_{L}\right)$. Then, for $\phi$ close enough to zero, there is a range of $\gamma>1 / 2$ such that $\tau_{2}=\tau_{1}$, and investment in legal capacity is lower than it would be if $\tau_{1}>\hat{\tau}\left(\theta, \alpha_{L}\right)$.

An immediate corollary of Propositions 3 and 4 is that, whenever initial fiscal capacity fulfills $\tau_{1}<\widehat{\tau}$, the opposition group in each period is not fully protected by the legal system. When political instability is high, the incumbent in period 1 does not want to expand the ability to tax, because it fears that such ability will be used to redistribute against its own group. As a result of the weak state, any period-2 incumbent uses inefficient legal protection to generate rents to the capital owners of its own group.

Proposition 4 thus describes an "investment trap", where political instability makes an incumbent group expect that larger state capacity will be used against its own interests. That expectation perpetuates an ineffective apparatus for tax raising, which causes inefficiencies in production. The situation persists because the probability of the common interest state $\left(\alpha_{s}=\alpha_{H}\right)$ is low.

\subsection{Implications}

We now develop some implications of these results for growth rates and the level of income. First, define the non-resource part of GDP as

$$
Y_{s}=Y\left(p^{I_{s}}, p^{O_{s}}\right)=\frac{y^{I_{s}}\left(p^{I_{s}}, p^{O_{s}}\right)+y^{O_{s}}\left(p^{I_{s}}, p^{O_{s}}\right)}{2} .
$$

With an inefficient regulatory policy in period $s$, income becomes $Y\left(\pi_{s}, 0\right)$, where by symmetry $Y\left(\pi_{s}, 0\right)=Y\left(0, \pi_{s}\right)$. This is clearly lower than the level with efficient legal protection $Y\left(\pi_{s}, \pi_{s}\right)$. 
Now consider two economies $S$ and $L$, where Propositions 3 and 4 apply. Assume that the same initial legal capacity $\pi_{1}^{S}=\pi_{1}^{L}=\pi_{1}$ prevails in both, but $\tau_{1}^{S}<\widehat{\tau}\left(\theta^{S}, \alpha_{L}\right)$ and $\tau_{1}^{L}>\widehat{\tau}\left(\theta^{L}, \alpha_{L}\right)$ so that the economies find themselves at opposite sides of the fiscal-capacity threshold, either because of different initial fiscal capacities, $\tau_{1}^{S}<\tau_{1}^{L}$, or because of different inclusiveness in political institutions, $\widehat{\tau}\left(\theta^{L}, \alpha_{L}\right)<\widehat{\tau}\left(\theta^{S}, \alpha_{L}\right)$ as $\theta^{L}>\theta^{S}$.

Let us compare income levels in periods 1 and 2. It follows from Proposition 3 that

$$
Y_{1}^{L}-Y_{1}^{S}=Y\left(\pi_{1}, \pi_{1}\right)-Y\left(\pi_{1}, 0\right)>0,
$$

i.e., in period 1, economy $S$ has a lower income level due to the inefficient legal protection of the opposition group. As the conditions in Proposition 4 hold, we have

$$
Y_{2}^{L}-Y_{2}^{S}=Y\left(\pi_{2}^{L}, \pi_{2}^{L}\right)-Y\left(\pi_{2}^{S}, 0\right)>Y\left(\pi_{1}, \pi_{1}\right)-Y\left(\pi_{1}, 0\right),
$$

where the inequality follows from the fact that $\pi_{2}^{L}>\pi_{2}^{S}$. Due to its low fiscal capacity, economy $S$ pursues a policy of less efficient legal protection than economy $L$ in period 2, whichever group is in power. But Proposition 4 tells us that economy $S$ has also invested less in legal capacity than economy $L$. The larger state not only has the higher GDP level, but its income advantage to the smaller state is growing over time.

These implications of Proposition 3 and 4 suggest another possible interpretation of the correlations in Figure 1. Using the results in Section 1, we may observe large government together with high income because the two are jointly determined by other factors, or because high income causes large government (recall Proposition 2). The results in this section suggest that a large state can actually cause high income, to the extent it limits policies that distort production. ${ }^{9}$

It is interesting to think about what may be ways out of inefficient legal protection or an investment trap? Propositions 3 and 4 suggests two possible answers: political reform and exogenous circumstance. Political reform that introduced more inclusive political institutions (a higher value of $\theta$ ) may shift the boundary value $\widehat{\tau}(\theta, \alpha)$ below existing fiscal capacity. A reform that diminished political instability (lower value of $\gamma$ ) may also induce first-period investment. Exogenous circumstance, such as a higher likelihood or expected severity of external conflict (higher $\phi$ or $\alpha_{H}$ ), may make it too costly to pursue

\footnotetext{
${ }^{9}$ Of course, our caveat noted above about not considering tax distortions still applies.
} 
inefficient legal protection by raising the prospect of a future common-interest state.

Let us return briefly to the work on political origins of financial development mentioned in Section 1, which argues that a desire to create or preserve rents can prevent a ruling elite from building the institutions needed for wellfunctioning financial markets (see e.g., Rajan and Zingales, 2003 or Pagano and Volpin, 2005). This work generally considers the financial sector without reference to the tax system. So, the political-origins argument may implicitly assume a lack of fiscal capacity, which makes it unattractive for the incumbents to invest in private markets, maximize income, and instead carry out its desired redistribution via taxes and transfers. As stressed by Acemoglu (2003, 2006), it is important to pose the political Coase-theorem question explicitly, and our analysis here suggests a new way of doing so. But the key innovation is to think of both aspects of state capacity as evolving together and influencing policy incentives.

We believe that the argument is much more general than the specific example in this section. Further work might consider the joint determination of weak states and other policy-induced production distortions, such as tariffs or red-tape regulation.

\section{State capacity and the strategy of conflict}

Our discussion about the origins of state capacity highlighted the risk of external conflict as a possible interpretation of $\alpha_{s}$. But all conflict is not external - internal conflicts plague many states particularly in the third world. Counting all countries and years since 1950, the incidence of civil war is about $6 \%$, with a yearly peak of more than $12 \%$ (in 1991 and 1992), according to the Correlates of War data set. Figure 2a shows the variable time path of the worldwide prevalence of civil war. The cumulated death toll in civil conflicts since the Second World War exceeds 15 million (Lacina and Gledtisch, 2005).

The causes of civil war are subject to a large theoretical and empirical literature in political science and economics (see e.g., Sambanis, 2002 and Blattman and Miguel, 2009 for broad reviews). A robust empirical fact is that poor countries are disproportionately more likely to be involved in civil war, even though the direction of causation may be difficult to establish. ${ }^{10}$

\footnotetext{
${ }^{10}$ Miguel, Satyanath and Sergenti (2004) use weather shocks to instrument for growth in African countries from the 1980s and onwards, and find that lower growth raises the
} 
The concentration of internal conflict in poor countries is shown in Figure $2 \mathrm{~b}$, which plots the share of years with civil war since 1950 (or independence, if later) against GDP per capita in the year 2000. Civil war is thus closely linked to development. There are two leading interpretations of this correlation in the literature: Fearon and Laitin (2003) see conflict in poor countries as reflecting limited state capacity to put down rebellions, while Collier and Hoeffler (2004) see it as reflecting lower opportunity costs of fighting in lowincome economies. There is also considerable debate about other suggested drivers of civil war, such as natural resource rents, ethnic conflicts, and political institutions.

The civil war literature typically treats variables such as incomes and state capacity as exogenous. A fuller understanding of these issues needs a theory where dynamic incentives to increase state capacity are considered in light of the propensity of future conflict. The route we take in this section is to recognize that the redistributive state when $\alpha_{s}=\alpha_{L}$ may lead to competition for state control, as the winner becomes a residual claimant on public resources. While external conflict can be described mainly as a source of common interests across groups in a state, internal conflict is a graphic manifestation of conflicting interests across groups. As Besley and Persson (2008b) argue - theoretically and empirically - the two forms of conflict may therefore have opposite effects on the incentives to invest in fiscal capacity.

Our analysis also contributes to discussions of the "resource curse" the claim that resource-rich countries tend to grow more slowly. A possible reason is that resource rich countries tend to be more conflict prone. ${ }^{11}$ Here, we highlight a possible mechanism working through investments in state capacity.

To make these points, we marginally extend the framework in Section 1 by allowing for the possibility that public and private resources are used to gain control of the state. We then consider how the possible future deployment of resources to conflict affects the incentives of a current incumbent to invest in state capacity.

probability of civil conflict.

${ }^{11}$ See Ross (2004) for a survey of the research on natural resources ansd civil war. 


\subsection{Conflict and takeover}

We assume that power may be transferred peacefully, as was implicitly the case in Section 1, as well as after a violent conflict where each group raises an army to fight. To be specific, we suppose that the incumbent can raise an army, the size of which (in per capita terms) is denoted by $\delta^{I_{s-1}}=\left\{0, A^{I}\right\}$, where $0<A^{I}<1$ (the size of the total population is unity). This discretechoice formulation, which is relaxed in Besley and Persson (2008c), is somewhat artificial but makes the analysis simpler. There is no conscription, so soldiers are simply compensated for their lost income. The army, which costs $w^{I_{s-1}} \delta^{I_{s-1}}$, is financed out of the public purse. Decisions on the army is subject to the same political constraints as decisions on policy. Hence, as above, the incumbent policy maker internalizes the preferences of the opposition group using weight $\theta .{ }^{12}$

The opposition can also raise an army denoted by $\delta^{O_{s-1}} \in\left\{0, A^{O}\right\}$, with $0<A^{O}<1$, which it uses to mount an insurgency to take over the government. When in opposition, we assume that each group has the capacity to tax its own citizens in order to finance a private militia. The decision on $\delta^{O_{s-1}}$ is made by the opposition group and is not subject to any political constraints, but the resources have to be raised within the group.

The probability that group $O_{s-1}$ wins power and becomes the new incumbent $I_{s}$ is

$$
\gamma\left(\delta^{O_{s-1}}, \delta^{I_{s-1}}\right) .
$$

This depends on the resources devoted to fighting. We assume that $\gamma$ is increasing in its first argument and decreasing in the second. Below, we assume a specific functional-form, which yields a closed-form solution.

There are thus two substantive changes to the model described in Section 1.1. First, the government budget constraint has to be rewritten to reflect the financing of the state army. This is now ${ }^{13}$

$$
0 \leq \sum_{J_{s} \in\left\{I_{s}, O_{s}\right\}} \frac{t^{J_{s}} w^{J_{s}}}{2}-G_{s}+z_{s}-w^{I_{s-1}} \delta^{I_{s-1}} .
$$

\footnotetext{
${ }^{12}$ This formulation differs slightly from Besley and Persson (2008c) who assume that institutional constraints bind ex post rather than ex ante. However, the results are quite similar.

${ }^{13}$ This formulation assumes that resource revenues are large enough to finance the incumbent's army or, alternatively, that the new incumbent pays for the army ex post, honoring any outstanding "war debts".
} 
Second, stage 3 in the timing is replaced by the sequence:

3a. Group $O_{s-1}$ chooses the level of any insurgency $\delta^{O_{s-1}}$.

$3 \mathrm{~b}$. The incumbent government $I_{s-1}$ chooses the size of its army $\delta^{I_{s-1}}$.

3c. Group $I_{s-1}$ remains in office with probability $1-\gamma\left(\delta^{O_{s-1}}, \delta^{I_{s-1}}\right)$.

We interpret civil war in this setting as $\delta^{O_{s-1}}=A^{O}$ and $\delta^{I_{s-1}}=A^{I}$, i.e. both groups are raising armies.

\subsection{Incidence of civil war and repression}

Preliminaries It is easy to show that the (new) incumbent's policy choices at stage 4 of each period in Proposition 1 still apply. We can use this to write the government's objective function after the resolution of uncertainty over $\alpha_{s}$ and $R_{s}$ has been realized at the end of stage 2 , but prior to the choice of armies at stage 3 . For the incumbent at stage $3 \mathrm{~b}$, the appropriate expression depends on the realized value of $\alpha_{s}$ and is given by

$E\left[V^{I_{s-1}}\left(\pi_{s}, \tau_{s}\right) \mid \alpha_{s}=\alpha_{H}\right]=\alpha_{H}\left[\tau_{s} w\left(\pi_{s}\right)+z_{s}-w\left(\pi_{s}\right) \delta^{I_{s-1}}\right]+w\left(\pi_{s}\right)\left(1-\tau_{s}\right)$

and, after some algebra, we also have

$$
\begin{gathered}
E\left[V^{I_{s-1}}\left(\pi_{s}, \tau_{s}\right) \mid \alpha_{s}=\alpha_{L}\right]=w\left(\pi_{s}\right)\left(1-\tau_{s}\right) \\
+\left[(1-\theta)-\gamma\left(\delta^{O_{s-1}}, \delta^{I_{s-1}}\right)(1-2 \theta)\right] 2\left[\tau_{s} w\left(\pi_{s}\right)+z_{s}-w\left(\pi_{s}\right) \delta^{I_{s-1}}\right] .
\end{gathered}
$$

Unconstrained by any common political institution, the opposition chooses its army $\delta^{O_{s-1}}$, at stage 3a, to maximize the group's expected utility. This also depends on $\alpha_{s}$ and is given by

$E\left[V^{O_{s-1}} \mid \alpha_{s}=\alpha_{H}\right]=\alpha_{H}\left[\tau_{s} w\left(\pi_{s}\right)+z_{s}-w\left(\pi_{s}\right) \delta^{I_{s-1}}\right]+w\left(\pi_{s}\right)\left(1-\tau_{s}-\delta^{O_{s-1}}\right)$,

and

$$
\begin{aligned}
& E\left[V^{O_{s-1}} \mid \quad \alpha_{s}=\alpha_{L}\right]=\gamma\left(\delta^{O_{s-1}}, \delta^{I_{s-1}}\right) 2\left[\tau_{s} w\left(\pi_{s}\right)+z_{s}-w\left(\pi_{s}\right) \delta^{I_{s-1}}\right] \\
& +w\left(\pi_{s}\right)\left(1-\tau_{s}-\delta^{O_{s-1}}\right) .
\end{aligned}
$$

Equilibrium armies We now characterize the sub-game perfect equilibrium where the insurgents (opposition) move first. We denote this by $\left\{\widehat{\delta}^{O_{s-1}}, \widehat{\delta}^{I_{s-1}}\right\}$. We begin by stating a useful (if perhaps obvious) result: 
Proposition 5 There is never any conflict when $\alpha_{s}=\alpha_{H}: \widehat{\delta}^{O_{s-1}}=\widehat{\delta}^{I_{s-1}}=$ 0 .

Intuitively, all spending will be on common-interest goods independently of who holds power, so there is nothing to fight over.

In redistributive states, $\alpha_{s}<2(1-\theta)$, the situation is different. The payoffs (12) and (14) reveal a basic underlying trade-off: decision makers must weigh the opportunity cost of higher armed forces against a higher probability of takeover and control over the redistributive cake. To study that trade-off we make

\section{Assumption 1}

(a) The technology for conflict is: $\gamma\left(\delta^{O}, \delta^{I}\right)=\mu\left[\delta^{O}-\delta^{I}\right]+\gamma^{O}$

(b) $\mu A^{I} \leq \gamma^{O} \leq 1-\mu A^{O}$

(c) $\frac{1}{2}+\gamma^{O}-\mu A^{I} \geq \frac{1-\theta}{1-2 \theta}$.

Part (a) says that a "linear probability model" governs the outcome of any conflict, while the peaceful turnover rate is $\gamma^{O}$. Restriction (b) on parameters guarantees a probability of turnover strictly between 0 and 1 , and will hold if $\mu$ is small enough. Restriction (c) says that the peaceful turnover probability $\gamma^{0}$ are large enough, or the political weight on the opposition $\theta$ is small enough. Essentially, this defines the parameter range in this model where conflict is a real threat.

Given Assumption 1, we get a straightforward characterization of conflict regimes by the size of public revenues and other parameters in terms of three main regimes. Define

$$
Z\left(z_{s} ; \pi_{s}, \tau_{s}\right)=\frac{\tau_{s} w\left(\pi_{s}\right)+z_{s}}{w\left(\pi_{s}\right)}
$$

as the ratio of total government revenue per capita to the real wage (nonresource share of GDP). Next, define a lower and an upper bound for this variable:

$$
\underline{Z}=\frac{(1-\theta)-\gamma^{O}(1-2 \theta)}{(1-2 \theta) \mu}+A^{I} \text { and } \bar{Z}=\frac{1}{2 \mu}+A^{I} .
$$

We now have:

Proposition 6 Suppose that Assumption 1 holds and $\alpha_{s}=\alpha_{L}$ (a redistributive state), then there are three possibilities. 
1. If $Z\left(z_{s} ; \pi_{s}, \tau_{s}\right)>\bar{Z}$, then there is civil conflict with $\widehat{\delta}^{O_{s-1}}=A^{O}$ and $\widehat{\delta}^{I_{s-1}}=A^{I}$.

2. If $\underline{Z} \leq Z\left(z_{s} ; \pi_{s}, \tau_{s}\right) \leq \bar{Z}$, then the state is repressive with $\widehat{\delta}^{O_{s-1}}=0$ and $\widehat{\delta}^{I_{s}-1}=A^{I}$.

3. If $Z\left(z_{s} ; \pi_{s}, \tau_{s}\right)<\underline{Z}$, then there is peace with $\widehat{\delta}^{O_{s-1}}=0$ and $\widehat{\delta}^{I_{s-1}}=0$.

If $Z\left(z_{s} ; \pi_{s}, \tau_{s}\right)$ is very high which corresponds to low wages (low $\left.\pi_{s}\right)$, high fiscal capacity, high natural resource rents, or non-inclusive political institutions, then there is a conflict because it is cheap to fight and there is a lot to redistribute so that the winner of conflict gets a share of a larger cake. If $Z\left(z_{s} ; \pi_{s}, \tau_{s}\right)$ is in an intermediate range, then the government represses the opposition to increase the probability that it stays in power. Finally, if $Z\left(z_{s} ; \pi_{s}, \tau_{s}\right)$ is low enough, then there is peace. ${ }^{14}$

This proposition gives a link between natural resource rents, real wages, and the likelihood of conflict. For given state capacities $\left(\pi_{s}, \tau_{s}\right)$, the variable $Z_{s}$ varies stochastically with natural resource rents, $R_{s}$ and real wages, $w_{s}$. By this route, we expect commodity prices to predict civil war. Besley and Persson (2008c) explore the empirical link between commodity prices and the incidence of civil conflict. Using trade volume data from the NBER-UN Trade data set, and international price data for about 45 commodities from UNCTAD, they construct country-specific commodity export and commodity import price indexes for about 125 countries since $1960{ }^{15}$ According to the open-economy model in Besley and Persson (2008c), higher export price index can be interpreted as a positive shock to natural resource rents, and a higher import price index as a negative shock to (real) income. In line with Proposition 6 , they find a robust empirical link between these price indexes and the incidence of civil war.

Proposition 6 also suggests that government repression and civil war may reflect the same underlying determinants, namely resource rents, real wages

\footnotetext{
${ }^{14}$ The parameter restriction in Assumption 1c, is the reason that the ordering is straightforward. In Besley and Persson (2008c), we also obtain an ordering result of this form (under weaker assumptions) in a related model where the choice of armies is continuous and institutions constrain the behavior of the incumbent and opposition ex post. For some parameter restrictions, it is possible to have an outcome where the government does not defend against an insurgency (passive acceptance of terrorism).

${ }^{15}$ The price indexes for a given country have fixed weights, computed as the share of exports and imports of each commodity in the country's GDP in a given base year.
} 
and political institutions. Indeed, the proposition suggests that the regimes of peace, repression, and civil war can be looked upon as ordered states. Interpreting government repression as infringements on human rights, Besley and Persson (2009) push this argument further and estimate the likelihood of observing these two states as an ordered probit.

\subsection{Investment in state capacity}

Our analysis in Section 3.2 takes legal and fiscal capacity as given. The next step is to ask how the risk of civil war affects the incentive to invest in state capacity, to deepen our understanding of how conflict shapes the prospects for state development.

When there is no risk of future civil war, the analysis in Section 1.3 applies with $\gamma^{O}=\gamma$. To simplify the algebra, while highlighting the new mechanisms added by the possibility of conflict, we assume that the period 1 incumbent knows for sure that the value of public goods in the future is low, i.e., that $\alpha_{2}=\alpha_{L}$ so that there is a risk of conflict. Except for the uncertain future incumbency, the only remaining uncertainty is thus about the level of natural resource rents. There are now two main effects to consider that are additional to those that we found in the non-conflict model.

The first of these comes from observing that conflict changes the probability that the incumbent group will stay in power and hence affects the political discount factor. To see this formally, we can use the result in Proposition 6 to write the equilibrium probability of turnover as:

$$
\Gamma\left(Z\left(R_{2} ; \pi_{2}, \tau_{2}\right)\right)= \begin{cases}\gamma^{O}+\mu\left[A^{O}-A^{I}\right] & \text { if } Z\left(R_{2} ; \pi_{2}, \tau_{2}\right)>\bar{Z} \\ \gamma^{O}-\mu A^{O} & \text { if } Z\left(R_{2} ; \pi_{2}, \tau_{2}\right) \in[\underline{Z}, \bar{Z}] \\ \gamma^{O} & Z\left(R_{2} ; \pi_{2}, \tau_{2}\right)<\underline{Z} .\end{cases}
$$

This probability depends on the exogenous level of resource rents, and on the endogenous levels of state capacity. This probability is not monotonic in the level of natural resources; survival is largest in the middle range where the government represses the opposition. Whether outright conflict leads to more or less political instability than peace depends upon whether $A^{O} \gtreqless A^{I}$.

The second effect of adding conflict to the model comes from the fact that the incumbent government has to pay the real market wage to employ the soldiers in its army. Thus, it may be more reluctant, all else equal, to raise incomes by investing in legal capacity (or any other institution raising the wage). 
We consider two cases. In Case 1, a country cycles between peace and civil war whereas in Case 2 it cycles between repression and civil war.

Case 1: $Z\left(R_{H} ; \pi_{2}, \tau_{2}\right)>\bar{Z}>\underline{Z}>Z\left(R_{L} ; \pi_{2}, \tau_{2}\right) \quad$ In this case, the prize from winning a conflict is high enough for the both the incumbent and the opposition to arm when resource rents are high, whereas neither of them wants to arm when resource rents are low. Implicitly, we thus assume that variations in investment in fiscal capacity $\tau_{2}$ are never large enough to induce changes in the conflict regime.

Under these assumptions, and following the same approach as in Section 1 , we can write the payoff of the period-one incumbent controlling the statecapacity investment decisions as:

$$
\begin{gathered}
E\left[V^{I_{s}}\left(\pi_{2}, \tau_{2}\right) \mid \alpha_{s}=\alpha_{L}\right]=w\left(\pi_{2}\right)\left(1-\tau_{2}\right) \\
+E\left(\lambda_{2}\right)\left[\tau_{2} w\left(\pi_{2}\right)+E\left(z_{2}\right)\right] \\
-\rho\left[1-\theta-\left(\left(\mu\left(A^{O}-A^{I}\right)+\gamma^{O}\right)\right)(1-2 \theta)\right] 2 w\left(\pi_{2}\right) A^{I},
\end{gathered}
$$

where the expected value of future government funds is given by $E\left(\lambda_{2}\right)=$ $\left[1-\theta+\left(\mu \rho\left(A^{O}-A^{I}\right)+\gamma^{O}\right)(1-2 \theta)\right] 2$. As in Section 1, we focus on the case where $E\left(\lambda_{2}\right)>1$ so that investments in both kinds of state capacity remain complements. ${ }^{16}$ Compared to our earlier expression (4) in the baseline (no-conflict) model in Section 1, there is a new term on the third line which captures the cost of conflict. It is multiplied by $\rho$ to reflect the fact that conflict occurs only when resource rents are high.

The first-order conditions for investments in legal and fiscal capacity are:

$$
\begin{gathered}
w_{p}\left(\pi_{2}\right)\left[\left\{1+\tau_{2}\left[E\left(\lambda_{2}\right)-1\right]\right\}-\rho\left[1-\theta+\left(\mu\left(A^{I}-A^{O}\right)-\gamma^{O}\right)(1-2 \theta)\right] 2 A^{I}\right] \\
\leq \lambda_{1} L_{\pi}\left(\pi_{2}-\pi_{1}\right) \\
w\left(\pi_{2}\right)\left[E\left(\lambda_{2}\right)-1\right] \leq \lambda_{1} F_{\tau}\left(\tau_{2}-\tau_{1}\right) .
\end{gathered}
$$

We focus on the situation where $A^{I} \approx A^{O}$ which implies that the effect of conflict on political turnover is negligible as is the effect of $\rho$, the probability of conflict, on the expected value of public funds $E\left(\lambda_{2}\right)$. Then, the only effect on

\footnotetext{
${ }^{16}$ Note, however, that an increase in $\rho$ (now the probability of conflict since conflict occurs when natural resource rents are high) may increase or decrease the future expected value of public funds. Depending on the relative values of $A^{I}$ and $A^{O}$, this can raise or cut the likelihood that state capacities are substitutes rather than complements.
} 
investments of a higher probability of conflict comes from the second term on the left-hand side of (16). Evidently, a higher $\rho$ reduces the marginal return to investing in legal capacity. Taking the complementarity into account, we now have:

Proposition 7 Suppose that the future state is always redistributive ( $\alpha_{2}=$ $\left.\alpha_{L}\right)$, there is either conflict or peace depending on the level of natural resource rents, and that $A^{I} \approx A^{O}$. Then, an exogenous increase in the probability of conflict, via a higher value of $\rho$, reduces the incentive to invest in both fiscal and legal capacity.

When $A^{I} \approx A^{O}$ equilibrium political turnover is not changed, and conflict is Pareto inferior as it simply results in resources being spent without any material change in who holds power. Proposition 7 shows that the static inefficiency of conflict is compounded by a dynamic inefficiency through a lower incentive to invest in state capacity. This gives one underpinning of the link between conflict propensity and weak states.

Case 2: $Z\left(R_{H} ; \pi_{2}, \tau_{2}\right)>\bar{Z}>Z\left(R_{L} ; \pi_{2}, \tau_{2}\right)>\underline{Z}$ In this case, changes in resource rents cycle the economy between repression and civil war: the incumbent always finds it optimal to arm while the opposition only arms when resource rents are high. In this instance, the probability of high resource rents, $\rho$, has a direct effect on the discount factor of the period-one incumbent, even if $A^{I} \approx A^{O}$.

Now, the expected payoff to the incumbent is:

$$
\begin{aligned}
& E\left[V^{I_{s}}\left(\pi_{2}, \tau_{2}\right) \mid \alpha_{s}=\alpha_{L}\right]=w\left(\pi_{2}\right)\left(1-\tau_{2}\right) \\
& +E\left(\lambda_{2}\right)\left[\tau_{2} w\left(\pi_{2}\right)+E\left(z_{2}\right)-w\left(\pi_{2}\right) A^{I}\right],
\end{aligned}
$$

where $E\left(\lambda_{2}\right)=\left[1-\theta-\left(\mu\left(\rho A^{O}-A^{I}\right)+\gamma^{O}\right)(1-2 \theta)\right] 2$.

The first-order conditions for investing in state capacity become:

$$
\begin{gathered}
w_{p}\left(\pi_{2}\right)\left[\left\{1+\tau_{2}\left[E\left(\lambda_{2}\right)-1\right]\right\}-\left[1-\theta-\left(\mu\left(\rho A^{O}-A^{I}\right)+\gamma^{O}\right)(1-2 \theta)\right] 2 A^{I}\right] \\
\leq \lambda_{1} L_{\pi}\left(\pi_{2}-\pi_{1}\right) \\
w\left(\pi_{2}\right)\left[E\left(\lambda_{2}\right)-1\right] \leq \lambda_{1} F_{\tau}\left(\tau_{2}-\tau_{1}\right) .
\end{gathered}
$$

Again, we can contemplate the effect of a change in $\rho$ on the incentive to invest. From the first-order conditions, we have: 
Proposition 8 Suppose that in the future state is always redistributive $\left(\alpha_{2}=\right.$ $\alpha_{L}$ ) and there is either conflict or repression depending on the level of natural resource rents. Then, an increase in the exogenous probability of conflict, via a higher value of $\rho$, reduces the marginal incentive to invest in both fiscal and legal capacity.

The result follows again by complementarity, and by noting that a higher value of $\rho$ decreases the left hand side of both (20) and (19), the latter because $\frac{\partial L H S}{\partial \rho}=-2(1-2 \theta) \mu A^{O}\left(1-A^{I}\right)<0$. Intuitively, the direct effect on the discount factor always outweighs the effect on the expected value of fighting.

This result is analogous to part four of Proposition 2, whereby higher political instability reduces investments in state capacity. However, the instability is now modeled as an equilibrium outcome, where conflict (relative to repression) makes it less likely that the incumbent survives. Again, this result gives a theoretical underpinning to the notion that the prospect of conflict can underpin the perpetuation of weak states both in raising taxes and supporting markets.

\subsection{Implications}

Cases 1 and 2 above highlight two key mechanisms. They show how the possibility of conflict endogenously leads to states remaining weak with lower levels of wage income as a consequence. Our examples have focused on marginal incentives within a regime (corresponding to the assumptions that are maintained for the sake of defining out two cases). Proposition 6 defines a threshold above which conflict ends. In this case, a government may strive for a big enough investment in legal capacity to raise wages so as to generate peace. To the extent that this is important, we might expect incentives to go in the opposite way of those driving the results in Propositions 7 and 8 . There may then be scope for a "big push" to raise wages and to break out of the conflict trap.

The results provide a further reflection on the empirical literature on civil war mentioned in the introduction to this section. Our model suggests why it may be hazardous to consider the correlation between poverty and civil war as reflecting a causal effect from poverty to the incidence of conflict. Indeed, the theory suggests that the two leading explanations of this correlation low opportunity cost of fighting due to low wages, and low state capacity 
in poor countries - may both reflect common omitted factors rather than a causal mechanism. The results in this section illustrate the possibility that low state capacity in terms of raising tax revenue, as well as low wages, may be simultaneously determined with a high probability of civil war by factors such as high resource rents, or non-inclusive political institutions. This provides a note of caution for researchers who pursue empirical studies of the determinants of civil war.

More generally, this section illustrates the interesting but complex interactions between, state capacity, conflict and development. However, it also illustrates the logic of some common-sense propositions such as how successful political reform that diminishes the incidence of conflict can have dynamic benefits that strengthens state capacities.

\section{Final remarks}

In politics, history and sociology, state capacity is viewed as an important object of study. We have illustrated some simple ways of bringing the study of state capacity and its determinants into mainstream economics. In the development community, a lack of state capacity is often cited as a major obstacle to development. We have shown that legal capacity can be crucial for economic growth (in Section 1), that lack of fiscal capacity can contribute to low income (in Section 2), and that lack of legal capacity can contribute to the likelihood of civil war (in Section 3). Our analysis also suggests an important complementarity between these two forms of state capacity. This complementarity is a natural way to think about the clustering of institutions that appears to be a common feature of countries at different levels of development.

A few common themes emerge from the theoretical analysis in Sections 1 through 3. First, the institutional arrangements affecting public resource allocation, represented in the model by $\theta$, shape not only static policy incentives - determining the likelihood of a common-interest state - but they also have an impact on dynamic state development. Similarly, the level of economic development at a point in time affects policy outcomes, but also feeds dynamic state development. Finally, realized and prospective shocks to public revenues and public-good preferences have both static and dynamic effects on policies and state development.

We have highlighted the distinction between circumstances where the 
state is mainly used as a vehicle to pursue common-interest goals and circumstances where it is mainly used to redistribute income. With this distinction, (threats of) external and internal conflict have opposite effects on the incentives to invest in state institutions.

Although our theory has already helped us approach the data in novel ways, the model and the variations we have developed are very simple. To understand better the long-run forces of development, it would be valuable to add private capital accumulation and go to develop a fully-fledged dynamic framework. Another natural extension would be to endogenize political institutions. Given the history of today's developed states, a reasonable conjecture - in line with some work in political science - is that the demand for more representative government increases with state capacity. This suggests the possibility of a complementarity between political and economic institutions, which deserves further study.

Its simplicity notwithstanding, we view the research agenda presented here as a first step towards disentangling some of the complex interactions between state capacity, conflict and development. 


\section{References}

[1] Acemoglu, Daron, [2003], "Why not a Political Coase Theorem: Social Conflict, Commitment, and Politics", Journal of Comparative Economics 31, 620-652.

[2] Acemoglu, Daron, [2005], "Politics and Economics in Weak and Strong States", Journal of Monetary Economics 52, 1199-1226.

[3] Acemoglu, Daron, [2006], "Modeling Inefficient Institutions", in Blundell, Richard, Whitney Newey, and Torsten Persson (eds.), Advances in Economic Theory and Econometrics: Proceedings of the Ninth World Congress of the Econometric Society, Cambridge University Press.

[4] Acemoglu, Daron, Ticchi, Davide, and Andrea Vindigni, [2007], "Emergence and Persistence of Inefficient States", unpublished typescript.

[5] Barro, Robert J., [1990], "Government Spending in a Simple Model of Endogenous Growth," Journal of Political Economy 98, 103-125.

[6] Barro, Robert J., and Xavier Sala-i-Martin, [1992], "Public Finance in Models of Economic Growth," Review of Economic Studies 59, 645-661.

[7] Benabou, Roland, [1997], "Inequality and Growth", NBER Macroeconomics Annual 1996, MIT Press.

[8] Besley, Timothy and Torsten Persson, [2008a], "The Origins of State Capacity: Property Rights, Taxation and Politics", NBER working paper No. 13028, forthcoming in the American Economic Review.

[9] Besley, Timothy and Torsten Persson, [2008b], "Wars and State Capacity", Journal of the European Economic Association 6, 522-530.

[10] Besley, Timothy and Torsten Persson, [2008c], "The Incidence of Civil War: Theory and Evidence", unpublished typescript.

[11] Besley, Timothy and Torsten Persson, [2009], "Repression or Civil War?, forthcoming in the American Economic Review, Papers and Proceedings.

[12] Blattman, Christopher and Edward Miguel, [2009], "Civil War," forthcoming in Journal of Economic Literature. 
[13] Brewer, John, [1989], The Sinews of Power: War, Money and the English State, 1688-1783, Knopf.

[14] Collier, Paul and Anke Hoeffler, [2004], "Greed and Grievance in Civil War", Oxford Economic Papers 56, 563-595.

[15] Cukierman, Alex, Sebastian Edwards and Guido Tabellini, [1992], "Seignorage and Political Instability", American Economic Review 82, 537-555.

[16] Diamond, Peter and James Mirrlees, [1971], "Optimal Taxation and Public Production: I Production Efficiency", American Economic Review 61, 8-27.

[17] Fearon, James and David Laitin, [2003], "Ethnicity, Insurgency and Civil War", American Political Science Review 97, 75-90.

[18] Hall, Robert and Chad Jones, [1999], "Why Do Some Countries Produce so Much More Output per Worker than Others?", Quarterly Journal of Economics 114, 83-116.

[19] King, Robert G. and Ross Levine, [1993], "Finance and Growth: Schumpeter Might Be Right", Quarterly Journal of Economics 108, 717-37.

[20] Lacina, Bethany Ann and Nils Petter Gleditsch, [2005] "Monitoring Trends in Global Combat: A New Dataset of Battle Deaths", European Journal of Population 21, 145-165.

[21] La Porta, Rafael, Lopez de Silanes, Florencio, Shleifer, Andrei, and Robert Vishny, [1998], "Law and Finance", Journal of Political Economy 106, 1113-55.

[22] Levi, Margaret, [1988], Of Rule and Revenue, University of California Press.

[23] Lijphart, Arend, [1999], Patterns of Democracy: Government Forms and Performance in Thirty-Six Countries, Oxford University Press.

[24] Mathias, Peter and Patrick O'Brien, [1976], "Taxation in Britain and France 1715-1810: A Comparison of the Social and Economic Consequences of Taxes Collected for the Central Governments", Journal of European Economic History 5, 601-650. 
[25] Migdal, Joel S., [1988], Strong Societies and Weak States: State-Society Relations and State Capabilities in the Third World, Princeton: Princeton University Press.

[26] Milgrom, Paul and Chris Shannon, [1994], "Monotone Comparative Statics", Econometrica 62, 157-80.

[27] Pagano, Marco and Paolo Volpin, [2005], "The Political Economy of Corporate Governance", American Economic Review 95, 1005-30.

[28] Persson, Torsten, Roland, Gerard, and Guido Tabellini, [2000], "Comparative Politics and Public Finance", Journal of Political Economy 108, 1121-61.

[29] Rajan, Raghuram and Luigi Zingales, [2003], "The Great Reversal: The Politics of Financial Development in the Twentieth Century", Journal of Financial Economics 69, 5-50.

[30] Ross, Michael (2004), "What Do We Know about Natural Resources and Civil War?", Journal of Peace Research 41, 337-356.

[31] Sambanis, Nicholas, [2002], "A Review of Recent Advances and Future Directions in the Quantitative Literature on Civil War", Defense and Peace Economics 13, 215-243.

[32] Stasavage, David, [2007], "Partisan Politics and Pubic Debt: The Importance of the 'Whig Supremacy' for Britain's Financial Revolution", European Review of Economic History 11, 123-53.

[33] Svensson, Jakob, [1998], "Investment, Property Rights and Political Instability: Theory and Evidence," European Economic Review 42, 13171341.

[34] Tilly, Charles, [1985], "Warmaking and State Making as Organized Crime", in Evans, Peter, Rueschemeyer, Dietrich, and Theda Skocpol (eds.), Bringing the State Back In, Cambridge University Press. 


\section{Appendix}

Proof of Proposition 2 Part 1 refers to a multiplicative upward shift of the wage function $w(\cdot)$, as this raises both $w\left(\pi_{2}\right)$ and $w_{p}\left(\pi_{2}\right)$ for any given $\pi$. Part 2 follows by observing that $\frac{\partial E\left(\lambda_{2}\right)}{\partial \phi}=\alpha_{H}-2[1-\theta-\gamma(1-2 \theta)]>0$. To prove parts 3 and 4 , we observe that $\frac{\partial E\left(\lambda_{2}\right)}{\partial \gamma}=-(1-\phi) 2(1-2 \theta)$, and $\frac{\partial E\left(\lambda_{2}\right)}{\partial \theta}=(1-\phi) 2(2 \gamma-1)$, which is positive as long as $\gamma \geq 1 / 2$. Finally, 5 refers to a multiplicative downward shift of either cost function $L(\cdot)$ or $F(\cdot)$.

Proof of Proposition 3 To prove Proposition 3, first observe that:

$$
l^{J_{s}}=\frac{w\left(p^{I_{s}}\right) 2(1-\sigma)}{\left[w\left(p^{I_{s}}\right)+w\left(p^{O_{s}}\right)\right] \sigma} .
$$

Hence, for all $p^{I_{s}}>p^{O_{s}}$

$$
\begin{aligned}
\frac{\partial y^{I_{s}}\left(p^{I_{s}}, p^{O_{s}}\right)}{\partial p^{I_{s}}} & =\left\{\left[\frac{\left[(1-\sigma)-\sigma l^{I_{s}}\right]}{2(1-\sigma)} \eta+1\right](1-\eta)\left(k\left(p^{I_{s}}, p^{O_{s}}\right)\right)^{\eta-1} \sigma w_{p}\left(p^{I_{s}}\right)\right\} \\
& =\left\{\left[\left[\frac{1}{2}-\frac{w\left(p^{I_{s}}\right)}{\left[w\left(p^{I_{s}}\right)+w\left(p^{O_{s}}\right)\right]}\right] \eta+1\right](1-\eta)\left(k\left(p^{I_{s}}, p^{O_{s}}\right)\right)^{\eta-1} \sigma w_{p}\left(p^{I_{s}}\right)\right\}>0
\end{aligned}
$$

and

$$
\begin{aligned}
\frac{\partial y^{I_{s}}\left(p^{I_{s}}, p^{O_{s}}\right)}{\partial p^{O_{s}}} & =\left\{\frac{\left[(1-\sigma)-\sigma l^{I_{s}}\right]}{2(1-\sigma)} \eta(1-\eta) k\left(p^{I_{s}}, p^{O_{s}}\right) \sigma w_{p}\left(p^{O_{s}}\right)\right\} \\
& =\left\{\left[\frac{1}{2}-\frac{w\left(p^{I_{s}}\right)}{\left[w\left(p^{I_{s}}\right)+w\left(p^{O_{s}}\right)\right]}\right] \eta(1-\eta) k\left(p^{I_{s}}, p^{O_{s}}\right) \sigma w_{p}\left(p^{O_{s}}\right)\right\}<0 .
\end{aligned}
$$

Thus, there is a conflict of interest between creating property rights for the ruling group and the non-ruling group.

In general, we can write the part of the government's objective function that depends upon $\left(p^{I_{s}}, p^{O_{s}}\right)$ as:

$$
V^{I_{s}}\left(p^{I_{s}}, p^{O_{s}} ; \psi\right)=\psi y^{I_{s}}\left(p^{I_{s}}, p^{O_{s}}\right)+y^{O_{s}}\left(p^{I_{s}}, p^{O_{s}}\right)
$$


where

$$
\psi=\psi(\theta, \alpha)=\left\{\begin{array}{cc}
\frac{1-\theta+\tau\left(\frac{\alpha}{2}-(1-\theta)\right)}{\theta+\tau\left(\frac{\alpha}{2}-\theta\right)} & \text { if } \alpha \geq 2(1-\theta) \\
\frac{(1-\theta)}{\theta+\tau(1-2 \theta)} & \text { otherwise } .
\end{array}\right.
$$

It is easy to check that $\psi(\theta, \alpha)$ is decreasing in $\theta$ and $\tau$, and also decreasing in $\alpha$ if $\alpha \geq 2(1-\theta)$. Moreover, as $\tau \rightarrow 1$ and/or $\theta \rightarrow 1 / 2, \psi \rightarrow 1$ (independently of the value of $\alpha$ ). In general, the condition for choosing $p_{s}^{J}$ is:

$$
\psi \frac{\partial y^{I_{s}}\left(p^{I_{s}}, p^{O_{s}}\right)}{\partial p_{s}^{J}}+\frac{\partial y^{O_{s}}\left(p^{I_{s}}, p^{O_{s}}\right)}{\partial p_{s}^{J}} \lesseqgtr 0 .
$$

Observe that

$$
\frac{\partial\left[y^{I_{s}}\left(p^{I_{s}}, p^{O_{s}}\right)+y^{O_{s}}\left(p^{I_{s}}, p^{O_{s}}\right)\right]}{\partial p^{J_{s}}}=(1-\eta)\left(k\left(p^{I_{s}}, p^{O_{s}}\right)\right)^{\eta} \sigma w_{p}\left(p^{J_{s}}\right)>0 .
$$

From this, we conclude that as $\tau \rightarrow 1$ and/or $\theta \rightarrow 1 / 2, p^{I_{s}}=p^{O_{s}}=\pi_{s}$, i.e., production efficiency obtains, since the incumbent maximizes total income $y^{I_{s}}\left(p^{I_{s}}, p^{O_{s}}\right)+y^{O_{s}}\left(p^{I_{s}}, p^{O_{s}}\right)$. Moreover, as $\theta \rightarrow 0$ and $\tau \rightarrow 0$, then $\psi \rightarrow \infty$ and the incumbent maximizes its own group's income $y^{I_{s}}\left(p^{I_{s}}, p^{O_{s}}\right)$, such that $p^{I_{s}}=\pi_{s}$ and $p^{O_{s}}=0$. The existence of the critical threshold now follows from the intermediate value theorem, given that $\psi(\theta, \alpha)$ is continuous in $\theta$ on $[0,1 / 2]$. The property that $\widehat{\tau}_{\theta}(\theta, \alpha)<0$ follows since $\psi$ is decreasing in both $\theta$ and $\tau$, while $\widehat{\tau}_{\alpha}(\theta, \alpha)<0$, when $\alpha \geq 2(1-\theta)$, follows since $\psi$ is decreasing in $\alpha$ in that domain.

Proof of Proposition 4 To prove the proposition, we note some useful preliminaries. It is straightforward to check that the income function has a convenient quasi-linear form:

$$
\hat{y}^{J_{s}}\left(\pi_{s}, \alpha\right)=(1-\sigma) \omega+\sigma w\left(p^{J_{s}}\left(\pi_{s}, \alpha\right)\right) \psi(\omega),
$$

where $\psi(\omega)$ is a homogenous convex function. Also, by Hotelling's lemma:

$$
l^{J_{s}}=-w\left(p^{J_{s}}\left(\pi_{s}, \alpha\right)\right) \psi^{\prime}(\omega) .
$$

Let

$$
\bar{\omega}\left(\pi_{s}\right)=(1-\eta)\left(\frac{\sigma\left[w\left(\pi_{s}\right)\right]}{1-\sigma}\right)^{\eta}
$$


and

$$
\underline{\omega}\left(\pi_{s}\right)=(1-\eta)\left(\frac{\sigma\left[w\left(\pi_{s}\right)+w(0)\right]}{2(1-\sigma)}\right)^{\eta} .
$$

denote equilibrium wages when the incumbent sets legal protection efficiently $\left(\bar{\omega}\left(\pi_{s}\right)\right)$ and inefficiently $\left(\underline{\omega}\left(\pi_{s}\right)\right)$. It is easy to check that $\bar{\omega}\left(\pi_{s}\right)>\underline{\omega}\left(\pi_{s}\right)$. The incumbent maximizes the expected period 2 benefits

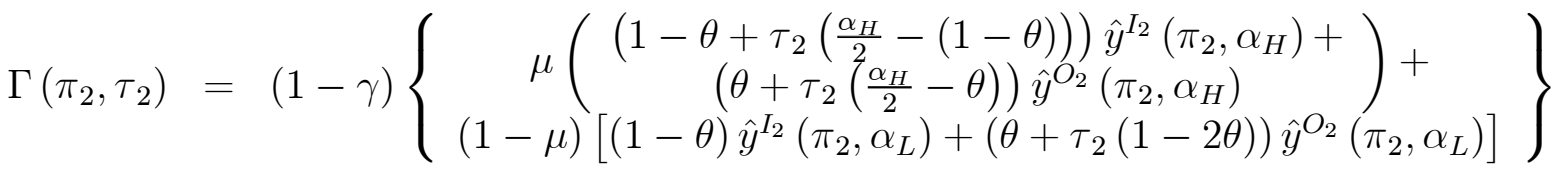

$$
\begin{aligned}
& +\gamma\left\{\begin{array}{c}
\mu\left(\begin{array}{c}
\left(1-\theta+\tau_{2}\left(\frac{\alpha_{H}}{2}-(1-\theta)\right)\right) \hat{y}^{O_{2}}\left(\pi_{2}, \alpha_{H}\right) \\
+\left(\theta+\tau_{2}\left(\frac{\alpha_{H}}{2}-\theta\right)\right) \hat{y}^{I_{2}}\left(\pi_{2}, \alpha_{H}\right)
\end{array}\right)+ \\
\left.(1-\mu)\left[1-\theta-(1-2 \theta) \tau_{2}\right] \hat{y}^{O_{2}}\left(\pi_{2}, \alpha_{L}\right)+\theta \hat{y}^{I_{2}}\left(\pi_{2}, \alpha_{L}\right)\right]
\end{array}\right\} \\
& =\mu\left\{\begin{array}{c}
\hat{y}^{I_{2}}\left(\pi_{2}, \alpha_{H}\right)\left[\frac{\alpha_{H}}{2}-[(1-2 \theta) \gamma-(1-\theta)]\left(1-\tau_{2}\right)\right]+ \\
\hat{y}^{O_{2}}\left(\pi_{2}, \alpha_{H}\right)\left[\frac{\alpha_{H}}{2}+[(1-2 \theta) \gamma-\theta]\left(1-\tau_{2}\right)\right]
\end{array}\right\} \\
& +(1-\mu)\left\{\left[\begin{array}{c}
((1-\gamma)-\theta(1-2 \gamma)) \hat{y}^{I_{2}}\left(\pi_{2}, \alpha_{L}\right)+ \\
{\left[(1-2 \gamma) \theta+\gamma-\tau_{2}(1-2 \gamma)(1-2 \theta)\right] \hat{y}^{O_{2}}\left(\pi_{2}, \alpha_{L}\right)}
\end{array}\right]\right\} .
\end{aligned}
$$

less the investment costs in period 1 . The marginal benefits with regard to the two choice variables are :

$$
\begin{aligned}
& \Gamma_{\tau}\left(\pi_{2}, \tau_{2}\right)=\mu\left(\begin{array}{c}
\hat{y}^{I_{2}}\left(\pi_{2}, \alpha_{H}\right)\left[\frac{\alpha_{H}}{2}+(1-2 \theta) \gamma-(1-\theta)\right] \\
+\hat{y}^{O_{2}}\left(\pi_{2}, \alpha_{H}\right)\left[\frac{\alpha_{H}}{2}-(1-2 \theta) \gamma-\theta\right]
\end{array}\right) \\
& +(1-\mu)(1-2 \gamma)(1-2 \theta) \hat{y}^{O_{2}}\left(\pi_{2}, \alpha_{L}\right)
\end{aligned}
$$

and

$$
\begin{aligned}
\Gamma_{\pi}\left(\pi_{2}, \tau_{2}\right)= & \mu\left(\begin{array}{c}
\hat{y}_{\pi}^{I_{2}}\left(\pi_{2}, \alpha_{H}\right)\left[\frac{\alpha_{H}}{2}-[(1-2 \theta) \gamma-(1-\theta)]\left(1-\tau_{2}\right)\right] \\
+\hat{y}_{\pi}^{O_{2}}\left(\pi_{2}, \alpha_{H}\right)\left[\frac{\alpha_{H}}{2}+[(1-2 \theta) \gamma-\theta]\left(1-\tau_{2}\right)\right]
\end{array}\right) \\
& +(1-\mu)\left[\begin{array}{c}
((1-\gamma)-\theta(1-2 \gamma)) \hat{y}_{\pi}^{I_{2}}\left(\pi_{2}, \alpha_{L}\right)+ \\
{\left[(1-2 \gamma) \theta+\gamma-\tau_{2}(1-2 \gamma)(1-2 \theta)\right] \hat{y}_{\pi}^{O_{2}}\left(\pi_{2}, \alpha_{L}\right)}
\end{array}\right] .
\end{aligned}
$$

If $\mu \rightarrow 0$ and $\gamma>1 / 2$, we have that:

$$
\Gamma_{\tau}\left(\pi_{2}, \tau_{2}\right)=(1-2 \gamma)(1-2 \theta) \hat{y}^{O_{2}}\left(\pi_{2}, \alpha_{L}\right)<0,
$$


which implies that $\tau_{2}=\tau_{1}$. Moreover, as $\gamma \rightarrow 1 / 2$

$$
\begin{aligned}
\Gamma_{\pi}\left(\pi_{2}, \tau_{2}\right) & =\left[\begin{array}{c}
((1-\gamma)-\theta(1-2 \gamma)) \hat{y}_{\pi}^{I_{2}}\left(\pi_{2}, \alpha_{L}\right)+ \\
{\left[(1-2 \gamma) \theta+\gamma-\tau_{2}(1-2 \gamma)(1-2 \theta)\right] \hat{y}_{\pi}^{O_{2}}\left(\pi_{2}, \alpha_{L}\right)}
\end{array}\right] \\
& =\frac{1}{2}\left(\hat{y}_{\pi}^{I_{2}}\left(\pi_{2}, \alpha_{L}\right)+\hat{y}_{\pi}^{O_{2}}\left(\pi_{2}, \alpha_{L}\right)\right) \\
& =\frac{1}{2} \sigma w_{p}\left(\pi_{s}\right) \psi\left(\underline{\omega}\left(\pi_{s}\right)\right) \\
& <\sigma w_{p}\left(\pi_{s}\right) \psi\left(\bar{\omega}\left(\pi_{s}\right)\right) .
\end{aligned}
$$

This proves the result.

Proof of Proposition 5 The relevant objective functions when $\alpha_{s}=\alpha_{H}>$ $2(1-\theta),(11)$ and $(13)$, are strictly decreasing in $\delta^{I_{s-1}}$ and $A^{O_{s-1}}$, respectively.

Proof of Proposition 6 To solve for the equilibrium in Proposition 6, first observe that (using 12) the incumbent will set $\delta^{I_{s-1}}=A^{I}$ if:

$$
\mu(1-2 \theta) Z\left(z_{s} ; \pi_{s}, \tau_{s}\right) \geq(1-\theta)-\left[\gamma^{O}+\mu\left(\delta^{O_{s-1}}-\delta^{I_{s-1}}\right)\right](1-2 \theta) .
$$

This implies that a sufficient condition for $\delta^{I_{s-1}}=A^{I}$ is that

$$
Z\left(z_{s} ; \pi_{s}, \tau_{s}\right) \geq \underline{Z}
$$

We will show that this is also necessary.

A necessary and sufficient condition for $\delta^{O_{s-1}}=A^{O}$ is that:

$$
\mu 2 Z\left(z_{s} ; \pi_{s}, \tau_{s}\right) \geq 1+2 \mu \delta^{I_{s-1}}
$$

or

$$
Z\left(z_{s} ; \pi_{s}, \tau_{s}\right) \geq \bar{Z}-\left(A^{I}-\delta^{I_{s-1}}\right) .
$$

Assumption 1(c) implies that $\bar{Z}-A^{I}>\underline{Z}$. We now prove the result. Suppose first that $Z\left(z_{s} ; \pi_{s}, \tau_{s}\right) \geq \bar{Z}$. Then $\delta^{O_{s-1}}=A^{O}$ and, since $\bar{Z}>\underline{Z}$, we also have $\delta^{I_{s-1}}=A^{I}$ as claimed in part 1 of Proposition 6 . If $Z\left(z_{s} ; \pi_{s}, \tau_{s}\right) \in[\underline{Z}, \bar{Z}]$ then $\delta^{I_{s-1}}=A^{I}$ and hence $\delta^{O_{s-1}}=0$. Finally, consider what happens when $Z\left(z_{s} ; \pi_{s}, \tau_{s}\right)<\underline{Z}$. Since $\bar{Z}-A^{I}>\underline{Z}$, this implies that $\delta^{O_{s-1}}=0$. Thence $\delta^{I_{s-1}}=0$. 


\section{Figure 1 State capacities and income}

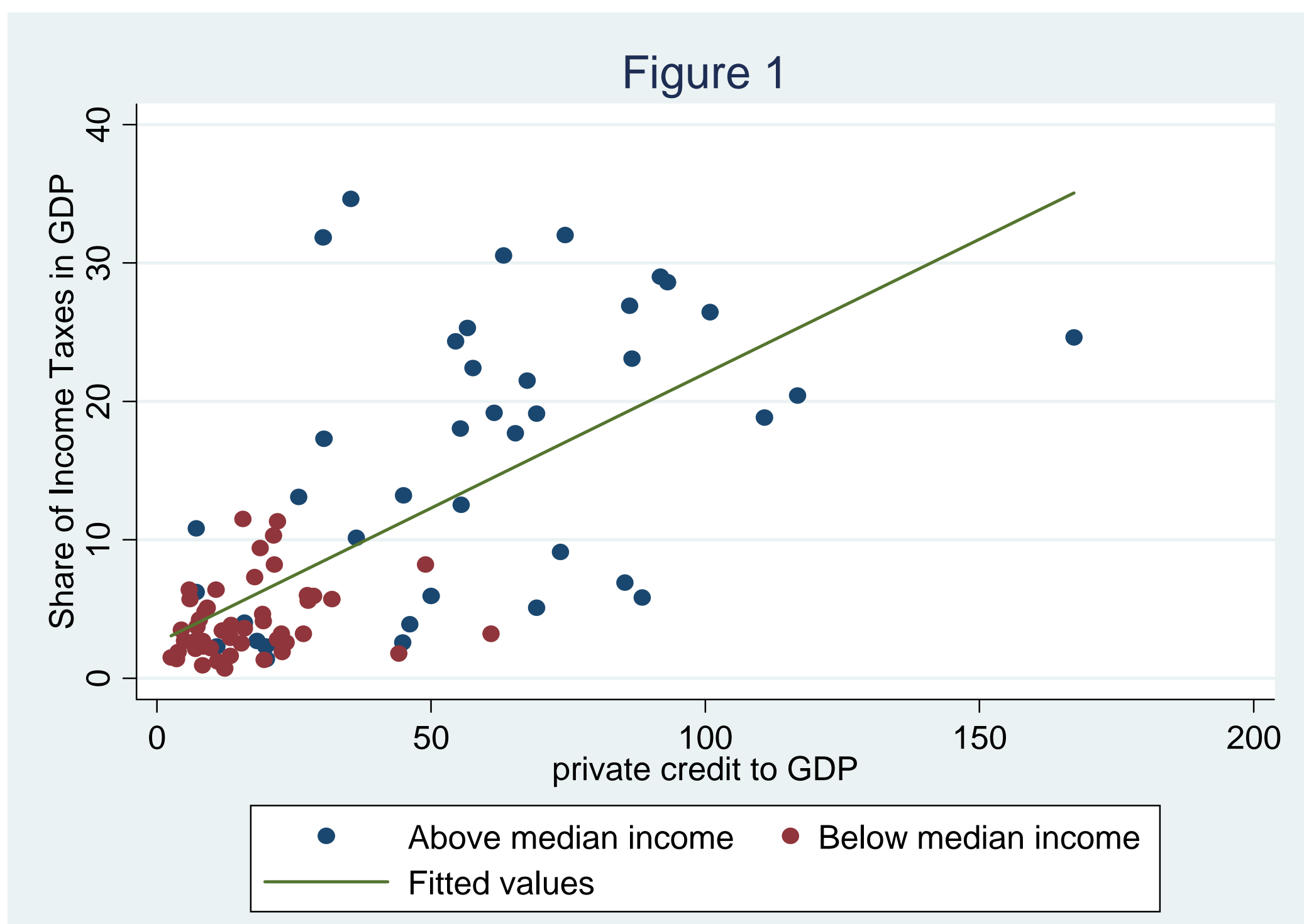

